\title{
Influence of Category and Grade of Vocational Qualification Certificate Holders on Career Development of Enterprise Employees
}

\author{
Cisheng Wu \\ College of Management \\ Hefei University of Technology \\ Hefei, China
}

\author{
Hao $\mathrm{Wu}^{*}$ \\ College of Management \\ Hefei University of Technology \\ Hefei, China
}

\author{
Yangyang Dang \\ College of Management \\ Hefei University of Technology \\ Hefei, China
}

\begin{abstract}
This paper presents a literature review of the origin, development, and theoretical basis of the professional qualification system in China. A survey is conducted to analyze three aspects: whether employees have a vocational qualification certificate, what kind of the certificate they have, and which level the certificate is of. Based on the collected data and statistics, the conclusion verifies that the vocational qualification certificate system has a positive effect on human resource management.
\end{abstract}

Keywords-vocational qualification certificate system; categories and grade level; effectiveness

\section{INTRODUCTION}

In 1993, the Chinese government proposed the idea of "establishing qualification standards and employment standards for various professions, and implementing an academic credential certificate system and a vocational qualification certificate system.” In July 1994, the state promulgated the Labor Law of the People's Republic of China, proposing that "the state shall implement the vocational qualification certificate system.” In the same year, the Ministry of Labor and the Ministry of Personnel jointly promulgated the Regulations on Vocational Qualification Certificates. These policies and laws and regulations formally established the vocational qualification certificate system (VQCS) in China [1]. However, with the emergence and use of vocational qualification certificates in all walks of life, some conditions that are unfavorable to the fairness of the labor market have also occurred.

First, an extremely large number of vocational qualifications exist. In some industries where these qualifications are necessary, various vocational qualifications have been constantly set up by trade associations and government departments at all levels. The existence of more than a dozen vocational qualifications in some industries has led to the proliferation of certificates. At the same time, the VQCS has given birth to numerous training programs and

Anhui social science fund project: Compilation and Research of 2018 Annual White Paper on Human Resource Management of Hefei High-tech Zone, project number: JS2018QTXM0186 examinations, thereby becoming a means for various institutions to obtain benefits [2]. Some young people have blindly pursued certificates for the sake of employment, but the actual utility of certificates is questioned due to the random authentication and chaotic management of their issuance. Responding to these issues, the State Council has cancelled 434 items of professional qualification licensing in 7 batches since 2013, including 154 qualifications for professional and technical personnel and 280 qualifications for skilled personnel.

Since its establishment, the VQCS has played a key role in standardizing the labor market, improving the quality of workers, and gradually enhancing the market economic system. Thus, the importance of the VQCS to the human resources management of enterprises and the individual workers in China remains a subject for discussion.

\section{THEORETICAL BACKGROUND AND HYPOTHESES}

A. Vocational Qualification, Vocational Qualification System, and Vocational Qualification Certificate System

In the Regulations on Vocational Qualification Certificate promulgated by the Ministry of Labor and the Ministry of Personnel (1995), vocational qualification is defined as "the basic requirement of knowledge, technology, and ability necessary for a certain profession.” Vocational qualifications include access and practicing qualifications. The qualifications are the starting point for the knowledge, skills, and abilities of a certain professional and technical worker; the practicing qualifications, the necessary qualifications for certain industries, are the access control implemented by the government for certain positions that involve great responsibility, strong social universality, and public interest.

Vocational qualification system (VQS) is a social activity system that establishes qualification standards in necessary industries in accordance with relevant laws and regulations formulated by the state, and evaluates and standardizes the 
basic conditions for social practitioners to engage in professional activities through certain procedures. The VQS in China can be divided into access qualification and level qualification. Access qualification is a type of access control conducted by laws and procedures, aiming at specific occupations such as public safety, personal health, and life and property safety. Level qualification is a type of occupation with strong social universality, professionalism, and high skill requirements.

China's VQCS consists of several professional and technical qualifications and vocational skills appraisal. Among them, professional and technical qualifications are similar to titles that reflect a person's academic and technical level, abilities, and achievements. The theoretical knowledge and practical operation ability that workers should master in a certain occupation are objectively measured by the examination and assessment organization, and those who pass the appraisal can obtain the professional qualification certificate. The main objects of vocational skill appraisal are production workers, machine operators, business service personnel, project managers, and psychological consultants, among others.

\section{B. Correlation Theory}

According to human capital theory, human capital is the resource embodied in people. People can improve their ability as producers by investing in their own capital mainly through education and training. Therefore, the greater the investment in human capital, the higher is the stock of production knowledge, labor, and management skills, which are conducive to the capacity enhancement and development of humans. Also from the perspective of theory, the higher the level of an employee's vocational qualification certificate, the greater is the investment in human capital and the higher is the human capital stock of the individual himself/herself, which can create greater value for an enterprise and help to improve the effectiveness of human resource management.

According to information economics theory, the higher the level of vocational qualification certificates held by workers in the labor market without sufficient information, the higher their professional level in this respect, and the more obvious are the signals of employability. In this way, employers can easily review workers' professional knowledge, simplify the recruitment process, reduce the risk of improper selection, and effectively match personnel and positions. Workers can also save energy and select suitable jobs. Therefore, the level of workers holding vocational qualification certificates is proportional to the effect of recruitment and selection.

According to the organizational learning theory, employees with vocational qualification certificates generally have high achievement motivation and strong learning ability; thus, they are likely to perform well at work. At the same time, the professional competence and quality acquired in the process of learning and examination to obtain qualification certificates also help to improve workers' performance. Therefore, employees with occupational qualification certificates are more likely to benefit their employers through good job performance. The higher the level of qualification, the better the performance.
In enterprises under a market economy, the individual's ability is generally proportional to the remuneration he/she receives. The higher the individual's ability, the higher the work performance and the greater is the likelihood to earn a higher remuneration. Therefore, employees with professional qualification certificates are more likely to earn a salary proportional to their grade.

Employees with vocational qualification certificates have high motivation to achieve, and their ability is easily recognized by others. These employees are more likely to participate in the organization and develop positive interpersonal relationships with their colleagues.

\section{Research Actuality}

The research on vocational qualification certification can be divided into "personal interest" theory [3-5] and "public interest" theory [6-8]. According to the theory of personal interest, the strict VQCS artificially restricts the supply of labor force and sets a threshold for entry into the industry. This restriction can increase the wages of industry practitioners. Although these practitioners gain benefits, the public interest is not improved and can even be damaged by the monopoly of the industry. The theory of public interest holds that professional qualification certification can improve the quality of practitioners, reduce the uncertainty faced by consumers on service quality, and motivate consumers to use high-quality services. Consequently, this situation stimulates practitioners to invest in human capital, thereby improving the overall quality of service and the public interest as a whole. Benham and Benham and Kwoka argue that with the acceleration of urbanization, and the problem of information asymmetry in product and service markets is becoming increasingly serious $[9,10]$. Employees who obtain professional qualification certifications are considered to have higher human capital and are able to provide consumers with higher quality services, thereby providing a quality signal to the market. Vocational qualification certifications enable consumers to distinguish between high-quality and low-quality service providers, and reduce consumers' uncertainty about product and service quality. According to Getz et al. and Conrad and Sheldon, the vocational qualification certification system can limit the number of new entrants by improving the certification standards and controlling the passing rate of examinations, increase the cost of workers entering the industry, limit the supply of labor force, and thus increase the income of practitioners [11,12]. Pashigian, Carroll and Gaston, and Shapiro argue, from the perspective of human capital investment, that obtaining vocational qualification certification requires passing difficult examinations, which are often accompanied by the requirements of work experience and educational background[13-15].

Chinese scholars have also conducted systematic research on vocational qualification certifications. Chen $\mathrm{Yu}$ described the historical development and current situation of China's VQS [16]. Shi Jintao and Chen Qi expounded on the essential attributes of the VQS from the viewpoint of human capital theory, believing that the formation process of the vocational qualification is essentially the process of transforming the enterprise-specific human capital into universal human capital 
[17]. The socialization process of human capital reduces the characteristics of the enterprise's human capital, and to a certain extent damages the core competence and competitive advantage of the enterprise. Xiao Lin studied the VQS from the perspective of regulation theory and stated that the five functions of the VQS were to (1) alleviate information asymmetry between consumers and service providers, (2) protect consumers, (3) control possible external effects, (4) protect those who lack self-protection, and (5) improve the income of service providers [18]. At the same time, occupational monopoly was believed to have the following negative effects: (1) harms the interests of consumers, (2) artificially increases the entry cost, (3) produces a distorted redistribution effect among consumers, and (4) hinders the normal development of innovation and service technology.

A literature review shows that the current research on VQS mainly focuses on macro-level theory, system analysis, and evaluation, whereas micro-level analysis and research are lacking on the implementation of VQS in enterprises and the individual characteristics of the holders of vocational qualification certificates.

\section{METHODS}

The questionnaire used in this study was divided into two parts: basic information and vocational qualification certificates.

The basic information part was mainly used to collect information on personal characteristic variables. The following subjects were set up:

(1) Gender.

(2) Age. According to the actual age of the respondents, they were divided into five groups: under 29 years old, 30-39 years old, 40-49 years old, 50-59 years old, and above 59 year old.

(3) Education level, which was divided into five groups: senior high school/secondary school and below, junior college, undergraduate, master, doctor and above.

(4) Work experience (in years), which was divided into five groups: under 1 year, 1-3 years, 3-5 years, 5-10 years, and over 10 years.

(5) Employment positions, which were divided into senior management, middle management, grassroots management, technical personnel, workers and other general employees.

The vocational qualification certificates part of the questionnaire mainly investigated the certificates held by the respondents and the company's value judgment of these certificates. A five-point Likert scale was used to indicate the answers to the following six questions:

(1) Do you hold a professional qualification certificate?

(2) What are the title, level, and year of the certificate?

(3) Is the certificate relevant to your current job?
(4) Is the certificate helpful for personal promotion?

(5) Does the company encourage certification?

(6) Does the company value vocational qualifications?

The subjects of this survey were mainly on-the-job employees that held national vocational qualification certificates, and several persons who did not have such certificates. The survey was conducted in three ways. First, we selected the representative enterprises in Hefei to conduct the concentrated survey. To survey focused mainly on manufacturing companies, but other types of enterprises were considered to collect the information on production and operation personnel. Second, we used the snowball method to send out questionnaires on the Internet and collect the responses. This method was intended to obtain information on business, service, and professional and technical personnel. Third, we sent questionnaires through the professional online questionnaire survey platform. As a supplement to the first two survey methods, this method made up for the shortage in some cases.

The questionnaire survey lasted for a month. A total of 500 questionnaires were sent out, among which 408 were recovered, accounting for a recovery rate of $81.6 \%$. Among the recovered questionnaires, 167 were sent out by enterprises on the spot, 161 were collected by online snowball survey, and 80 were collected by online survey. The valid questionnaires were 387, representing a validity rate of $94.9 \%$.

\section{RESUltS}

\section{A. Analysis of sample}

In terms of gender ratio, men accounted for $62.5 \%$ and women $37.5 \%$ of the respondents. In the field of production operation and engineering professional technology, the practitioners were mostly male, which was consistent with the actual situation.

In terms of age structure, $62.5 \%$ of the respondents were under 29 years old and 30.5\% were in the 30-39 age group, accounting for $93 \%$ of the total. These two age groups are the most dynamic in the labor market.

In terms of educational structure, the proportion of bachelor's degree was $45.2 \%$, junior college degree and below $20.2 \%$, and master's degree $24 \%$. Among them, the education level of production operation personnel was mainly junior college, senior high school and below; the professional and technical personnel mainly held bachelor's and master's degrees; and the comprehensive service personnel mainly held bachelor's degrees.

From the perspective of working life, the median was 3-5 years and a ladder shape was observed. Working life mainly concentrated on 1-10 years. This result was consistent with the age distribution of the subjects. 
TABLE I. BASIC INFORMATION

\begin{tabular}{|l|l|c|c|c|}
\hline \multirow{4}{*}{ Gender } & \multicolumn{1}{|c|}{ Category } & Frequency & Percentage (\%) & Cumulative percentage (\%) \\
\hline \multirow{4}{*}{ Age } & Male & 242 & 62.5 & 62.5 \\
\cline { 2 - 5 } & Female & 145 & 37.5 & 100 \\
\hline \multirow{5}{*}{ Education } & Under 29 & 242 & 62.5 & 62.5 \\
\cline { 2 - 5 } & $30-39$ & 118 & 30.5 & 93.0 \\
\cline { 2 - 5 } & $40-49$ & 25 & 6.5 & 99.5 \\
\cline { 2 - 5 } & $50-59$ & 2 & 5 & 100 \\
\hline \multirow{5}{*}{ Work Experience } & Senior high school and below & 43 & 11.1 & 11.1 \\
\cline { 2 - 5 } & Junior college and below & 74 & 19.1 & 20.2 \\
\cline { 2 - 5 } & Bachelor & 175 & 45.2 & 75.5 \\
\cline { 2 - 5 } & Master & 93 & 24.0 & 99.5 \\
\cline { 2 - 5 } & Doctor & 2 & 0.5 & 100.0 \\
\cline { 2 - 5 } & Under 1 year & 30 & 7.8 & 7.8 \\
\cline { 2 - 5 } & $1-3$ years & 90 & 23.3 & 31.0 \\
\cline { 2 - 5 } & 3-5 years & 111 & 28.7 & 59.7 \\
\cline { 2 - 5 } & 5-10 years & 102 & 26.4 & 86.0 \\
\cline { 2 - 5 } & Over 10 years & 54 & 14.0 & 100.0 \\
\hline \multirow{5}{*}{ Employment Positions } & Senior management & 10 & 2.6 & 2.6 \\
\cline { 2 - 5 } & Middle management & 55 & 14.2 & 36.8 \\
\cline { 2 - 5 } & Grassroots management & 76 & 19.6 & 66.7 \\
\cline { 2 - 5 } & Technicians & 117 & 30.2 & 89.9 \\
\cline { 2 - 5 } & Workers & 90 & 23.3 & 100.0 \\
\cline { 2 - 5 } & Other general employees & 39 & 10.1 & 100.0 \\
\hline & Total & 387 & 100.0 & \\
\hline
\end{tabular}

According to the position distribution, the proportions of senior management, middle management, grassroots management, technicians, workers, and other general employees were $2.6 \%, 14.2 \%, 19.6 \%, 30.2 \%, 23.3 \%$, and $10.1 \%$, respectively. The frequency distribution of positions was average, the frequency of middle and senior managers was low, and the frequency of technicians was high.

\section{B. Certificate Holdings}

Table 2 shows that 260 people hold certificates, accounting for $67.4 \%$ of the total survey. Among them, 205 people hold one certificate each, accounting for $53 \%$ of the total number of respondents, $11.6 \%$ hold two certificates, and $2.6 \%$ hold three certificates. To ensure the comparability of the survey results, we selected the employees who did not hold certificates in the same enterprise, department, or position as control.

\section{Category and Grade of Certificates Evaluation of Certificates Held}

As shown in Table 3, the proportion of professional and technical qualification certificates is the highest at $43.1 \%$, whereas that of comprehensive professional qualification certificates is only $12.7 \%$. To a certain extent, this result reflects the degree of acceptance of various types of certificates in the labor market.

In the level of certificates, the majority of the holders of levels 2 and 3 certificates accounted for $56.6 \%$ of the total. Certificates without grades are mainly qualification certificates for access, while certificates for levels 4 and 5 are mainly production and operation certificates, as shown in Table 4.
TABLE II. CERTIFICATE HOLDINGS

\begin{tabular}{|c|c|c|c|c|}
\hline & Category & Frequency & $\begin{array}{c}\text { Percentage } \\
\mathbf{( \% )}\end{array}$ & $\begin{array}{c}\text { Cumulative } \\
\text { percentage (\%) }\end{array}$ \\
\hline \multirow{2}{*}{$\begin{array}{c}\text { Whether } \\
\text { holding } \\
\text { certificates }\end{array}$} & Yes & 260 & 67.4 & 67.4 \\
\cline { 2 - 5 } & No & 127 & 32.6 & 100.0 \\
\cline { 2 - 5 } & Total & 387 & 100 & - \\
\cline { 2 - 5 } & 1 & 127 & 32.8 & 32.8 \\
\cline { 2 - 5 } $\begin{array}{c}\text { Certificates } \\
\text { number }\end{array}$ & 2 & 205 & 53.0 & 85.8 \\
\cline { 2 - 5 } & 3 & 10 & 11.6 & 97.4 \\
\cline { 2 - 5 } & Total & 387 & 2.6 & 100.0 \\
\hline
\end{tabular}

In the level of certificates, the majority of the holders of levels 2 and 3 certificates accounted for $56.6 \%$ of the total. Certificates without grades are mainly qualification certificates for access, while certificates for levels 4 and 5 are mainly production and operation certificates, as shown in Table 4.

\section{Evaluation of Certificates Held}

Among the respondents, $82.3 \%$ reported that holding a certificate was job-related or highly relevant, and $12.3 \%$ reported that holding a certificate was irrelevant or completely irrelevant to the existing job. Furthermore, $71.5 \%$ of the respondents believed that holding certificates was helpful for personal promotion, $11.9 \%$ thought it was very helpful for personal promotion, and $13.1 \%$ believed that holding certificates was not helpful for personal promotion. When investigating the attitude of enterprises toward vocational qualification certificates, $79.2 \%$ of the respondents reflected that the company encouraged employees to hold vocational qualification certificates, and $67.7 \%$ thought that the company attached great importance to vocational qualification certificates. Thus, we can observe that the vocational qualification certificates are meaningful to most employees and also recognized by most companies. 
TABLE III. TYPES AND GRADES OF CERTIFICATES

\begin{tabular}{|c|c|c|c|c|}
\hline & Category & Frequency & Percentage (\%) & Cumulative percentage (\%) \\
\hline \multirow{4}{*}{ Type of certificates } & Mechanical operation qualification & 58 & 22.3 & 22.3 \\
\cline { 2 - 5 } & Comprehensive qualification & 33 & 12.7 & 35.0 \\
\cline { 2 - 5 } & professional and technical qualification & 112 & 43.1 & 78.1 \\
\cline { 2 - 5 } & Practicing qualifications & 57 & 21.9 & 100.0 \\
\cline { 2 - 5 } & Total & 260 & 100.0 & - \\
\hline \multirow{4}{*}{ Level of certificates } & No grading & 24 & 21.9 & 21.9 \\
\cline { 2 - 5 } & Level 1 & 60 & 9.2 & 31.2 \\
\cline { 2 - 5 } & Level 2 & 87 & 23.1 & 54.2 \\
\cline { 2 - 5 } & Level 3 & 16 & 6.5 & 87.7 \\
\cline { 2 - 5 } & Level 4 & 16 & 6.2 & 93.8 \\
\cline { 2 - 5 } & Level 5 & 260 & 100.0 & 100.0 \\
\cline { 2 - 5 } & Total & & - \\
\hline
\end{tabular}

TABLE IV. THE GRADE DISTRIBUTION OF DIFFERENT TYPES OF CERTIFICATES

\begin{tabular}{|c|c|}
\hline & Category \\
\hline \multirow{5}{*}{$\begin{array}{c}\text { Mechanical operation } \\
\text { qualification }\end{array}$} & Level 2 (Technician) \\
\hline & Level 3 (Senior Technician) \\
\hline & Level 4 (Intermediate Technician) \\
\hline & Level 5 (Junior Technician) \\
\hline & Total \\
\hline \multirow{3}{*}{ Comprehensive qualification } & Level 2 \\
\hline & Level 3 \\
\hline & Total \\
\hline \multirow{4}{*}{$\begin{array}{c}\text { professional and technical } \\
\text { qualification }\end{array}$} & Level 1 (Senior) \\
\hline & Level 2 (Intermediate) \\
\hline & Level 3 (Assistant) \\
\hline & Total \\
\hline \multirow{2}{*}{ Practicing qualifications } & No grading \\
\hline & Total \\
\hline
\end{tabular}

\section{DISCUSSION}

Overall, the implementation of the VQCS has a positive effect on the employees of enterprises, thereby showing that the employees with vocational qualification certificates represent higher human capital, which is conducive to obtaining a reasonable job allocation; indicates willingness to participate in training and learning and other company activities; and contributes toward high performance, salary, and welfare, as well personal career security and career development space.

According to the data analysis, $82.3 \%$ of the respondents reported that holding certificates was related or very relevant to work, $71.5 \%$ believed that certificates contributed to personal promotion, and $13.5 \%$ believed that only professional qualification certificates did not help personal promotion. When investigating the company's attitude toward vocational qualification certificates, $79.2 \%$ of the respondents reflected that the company encouraged employees to hold vocational

\begin{tabular}{|c|c|c|}
\hline equency & Percentage (\%) & Cumulative percentage (\%) \\
\hline 8 & 13.8 & 13.8 \\
\hline 18 & 31.0 & 44.8 \\
\hline 16 & 27.6 & 72.4 \\
\hline 16 & 27.6 & 100.0 \\
\hline 58 & 100.0 & - \\
\hline 8 & 24.2 & 24.2 \\
\hline 25 & 75.8 & 100.0 \\
\hline 33 & 100.0 & - \\
\hline 24 & 21.4 & 21.4 \\
\hline 44 & 39.3 & 60.7 \\
\hline 44 & 39.3 & 100.0 \\
\hline 112 & 100.0 & - \\
\hline 57 & 100.0 & 100.0 \\
\hline 57 & 100.0 & - \\
\hline
\end{tabular}

qualification certificates, $67.7 \%$ thought that the company attached great importance to these certificates, and 13.5\% reflected that the company did not attach great importance to these certificates.

These data showed that professional qualification certificates were meaningful to most employees and also recognized by most companies. However, a considerable number of people believed that certificates were not helpful for personal promotion, and a considerable number of companies paid minimal attention to the VQCS.

Even in industries where the VQCS is common, such as human resources management, water conservancy, civil engineering, and construction, few people have obtained the certificate. Only in accounting and tour guiding industry, where vocational qualification certificates are necessary, and do employees have a large number of professional qualification certificates. This result shows that in addition to simple statistics, the actual situation shows that China's VQCS is not sufficiently universal.

TABLE V. EVALUATION OF CERTIFICATES Held

\begin{tabular}{|c|c|c|c|c|}
\hline & Category & Frequency & Percentage (\%) & Cumulative percentage (\%) \\
\hline \multirow{5}{*}{ Work-related or not } & Very relevant & 82 & 31.5 & 31.5 \\
\hline & Relevant & 132 & 50.8 & 82.3 \\
\hline & Hard to say & 14 & 5.4 & 87.7 \\
\hline & Basically irrelevant & 23 & 8.8 & 96.5 \\
\hline & Completely irrelevant & 9 & 3.5 & 100.0 \\
\hline \multirow{5}{*}{ Helpful for personal promotion or not } & Very helpful & 31 & 11.9 & 11.9 \\
\hline & Helpful & 155 & 59.6 & 71.5 \\
\hline & Hard to say & 39 & 15.0 & 86.5 \\
\hline & Basically unhelpful & 34 & 13.1 & 99.6 \\
\hline & Completely unhelpful & 1 & 0.4 & 100.0 \\
\hline
\end{tabular}




\begin{tabular}{|c|c|c|c|c|}
\hline \multicolumn{5}{|c|}{ Cont. to TABLE V. } \\
\hline \multirow{5}{*}{ Whether the company encourages } & Strongly encourage & 48 & 18.5 & 18.5 \\
\hline & encourage & 158 & 60.8 & 79.2 \\
\hline & Hard to say & 44 & 16.9 & 96.2 \\
\hline & Rarely encourage & 10 & 3.8 & 100.0 \\
\hline & No encouragement at all & 0 & 0 & 100.0 \\
\hline \multirow{5}{*}{ Whether the company attaches great importance } & Attaches great importance to & 31 & 11.9 & 11.9 \\
\hline & Attaches importance to & 145 & 55.8 & 67.7 \\
\hline & Hard to say & 49 & 18.8 & 86.5 \\
\hline & Undervalue & 33 & 12.7 & 99.2 \\
\hline & Pay no attention to & 2 & 0.8 & 100.0 \\
\hline
\end{tabular}

The limitation of this study is that it only explored the personal effect of vocational qualification certificates on practitioners and the degree of recognition of enterprises through a questionnaire survey. This study did not examine the effect of VQCS on the effectiveness of human resource management nor did it consider the effects of other factors on the effectiveness of vocational qualification certificates. Thus, further research on these subjects is necessary.

\section{REFERENCES}

[1] Yu Xingan, 2017 China Human Resources Development Report, Social Sciences Academic Press, 2017. (In Chinese)

[2] Qian Xiao-Ye, Chi Wei, Economic explanation of "certificate craze" -empirical analysis of income effect of vocational qualification certification in China [J]. Translated Edition of Economic Data, 2013, (2):24-36. (In Chinese)

[3] Friedman, M. and Kuznets S., "Income from Independent Professional Practice, NBER Chapters", in: Income from Independent Professional Practice, National Bureau of Economic Research, Inc, 1954, pp.95 173.

[4] Stigler George, "The theory of Economic Regulation”, Bell Journal of Economics and Management Science, Vol.1, No.1, pp.3 21, 1971.

[5] Shepard Lawrence, "Licensing Restrictions and the Cost of Dental Care", Journal of Law and Economics, Vol.21, No.1, pp.187 201, 1978.

[6] Maurizi Alex, "Occupational Licensing and the Public Interest", The Journal Of Political Economy, Vol. 82, No.2, Part 1, pp.399 413, 1974.

[7] Leland E. Hayne, "Quacks, Lemons, and Licensing: A theory Of Minimum Quality Standards”, The Journal of Political Economy, Vol. 87, No. 6, pp.1328 1346, 1979.
[8] Shapiro Carl, "Investment, Moral Hazard, and Occupational Licensing”, The Review of Economic Studies, Vol. 53, No. 5, pp.843 862, 1986.

[9] Benham Lee, Benham Alexandra, "Regulating through the Professions: A Perspective on Information Control”, Journal of Law and Economics, Vol. 18, No. 2, pp.421 447, 1975.

[10] Kwoka E. John Jr, "Advertising and the Price and Quality of Optometric Services”, American Economic Review, Vol. 74, No. 1, pp.211 216, 1984.

[11] Getz Malcolm, Siegfried John, Calvani Terry, "Competition at the Bar: the Correlation between the Bar Examination Pass Rate and the Profitability of Practice", Virginia Law Review, Vol. 67, No. 5, pp.863 885, 1981.

[12] Conrad A. Douglas, Sheldon G. George, "The Effects of Legal Constraints on Dental Care Prices”, Inquiry, Vol.19, No. 1, pp.51 67, 1982.

[13] Pashigian B. Peter, "Occupational Licensing and the Interstate Mobility of Professionals", Journal of Law and Economics, Vol. 22, No. 1, pp.1 25, 1979.

[14] Carroll L. Sidney, Gaston J. Robert, "Occupational Restrictions and the Quality of Service Received: Some Evidence”, Southern Economic Journal, Vol. 47, No. 4, pp.959 976, 1981.

[15] Carroll L. Sidney, Gaston J. Robert, "Occupational Licensing and the Quality of Service: An Overview”, Law and Human Behavior, Vol. 7, pp.139 146, 1983.

[16] Chen Yu. "Review and prospect of China's vocational qualification certificate system", Education and occupation, 2004, (1). (In Chinese)

[17] Shi Jin-tao, Chen qi. "Development of vocational qualification system: human capital theory", Scientific management research, 2003, (6):104108. (In Chinese)

[18] Xiao Lin, "Research on vocational qualification system from the perspective of regulation theory", China human resources development, 2008, (2). (In Chinese) 